\title{
Tapering from Methadone or Buprenorphine during Pregnancy: Maternal and Neonatal Outcomes in Norway 1996-2009
}

\author{
Gabrielle K. Welle-Strand ${ }^{a, b}$ Svetlana Skurtveit ${ }^{a, c}$ Lars Tanum $^{\text {a,d }}$ Helge Waal $^{a}$ \\ Brittelise Bakstad $^{\mathrm{b}} \quad$ Lisa Bjarkø $^{\mathrm{e}}$ Edle Ravndal ${ }^{\mathrm{a}}$ \\ ${ }^{a}$ SERAF - Norwegian Centre for Addiction Research, University of Oslo, b Norwegian Directorate of Health, \\ 'Department of Epidemiology, Norwegian Institute of Public Health, ${ }^{d}$ Department of Research and Development in \\ Psychiatry, Akershus University Hospital, and e Department of Pediatrics, Oslo University Hospital, Oslo, Norway
}

\section{Key Words}

Methadone · Buprenorphine · Pregnancy · Tapering ·

Norway

\begin{abstract}
Background: The tapering of methadone or buprenorphine during pregnancy is an understudied and controversial issue. The aim of this study was to determine to what extent women tapered their opioid medication dose during pregnancy and what the neonatal outcomes were for those who tapered compared to the women who did not. Methods: The study was a mixed prospective/retrospective national cohort study of 123 Norwegian women in opioid maintenance treatment (OMT) during pregnancy and their neonates. A standardized questionnaire was administered to the women and medical information that could be used for verification was collected from hospitals and municipalities. Results: Two of the women came off the OMT-medication during pregnancy and another 15\% tapered their OMT-medication dose more than $50 \%$. The birth weights of methadone-exposed neonates of the women who tapered more than $50 \%$ were significantly higher than for the methadoneexposed neonates of the women tapering between 11 and $50 \%$. No other significant differences were found. Conclusion: Pregnant women in OMT who taper their OMT-
\end{abstract}

(C) 2015 S. Karger AG, Basel

$1022-6877 / 15 / 0215-0253 \$ 39.50 / 0$ medication dose should be monitored closely. We need studies that document the maternal well-being and fetal safety of maternal tapering of the OMT-medication during pregnancy.

(c) 2015 S. Karger AG, Basel

\section{Introduction}

Opioid maintenance treatment (OMT) with either methadone or buprenorphine has become the treatment of choice for opioid-dependent pregnant women $[1,2]$. Forty to $90 \%$ of neonates exposed to methadone or buprenorphine in utero, will develop a neonatal abstinence syndrome (NAS) after delivery $[3,4]$. NAS is characterized by a multitude of symptoms which, although easy to identify in at-risk babies, may prove to be a challenge to treat and generally results in prolonged hospital stay. There seems to be general agreement that maternal withdrawal will also lead to fetal withdrawal, but the withdrawal in utero is difficult to monitor. The professionals cannot observe the fetal withdrawal in the same way as they observe the NAS of the neonate $[5,6]$.

Even though international and national treatment guidelines do not recommend pregnant women to taper their OMT-medication dose [7-9], some health profes-

\section{KARGER 125}

E-Mail karger@karger.com

www.karger.com/ear
Gabrielle K. Welle-Strand, MD

SERAF - Norwegian Centre for Addiction Research

Building 45, Oslo University Hospital, Ullevål

Box 1039 Blindern, NO-0315 Oslo (Norway)

E-Mail gwe@ helsedir.no 
sionals advise their patients to lower their OMT-medication dose during pregnancy, arguing that reducing the dose will lower the incidence and severity of NAS [1012]. Many pregnant women in OMT also want to lower their dose of methadone or buprenorphine, believing that this choice will be best for the development of their fetus. The scientific basis for this is debated, however.

The main reason for recommending women not to taper their OMT-medication dose during pregnancy is the increased risk of relapse to the use of illegal, short-acting opioids and other substances, which is more harmful both for the woman and for the fetus [13, 14]. Opioids have not been recognized to have teratogenic effects, although research indicates increasing concerns about visuocortical function [15-17].

Although a number of studies have focused on the relationship between the dose of methadone or buprenorphine at delivery and the incidence and duration of NAS for the neonate, the results have not been conclusive [1821]. Cleary's meta-analysis concludes that the severity of NAS does not seem to depend on high versus low dose of methadone toward the end of pregnancy [22]. This has been further confirmed in a recent study by Cleary et al. [23] describing methadone dosing in a prospective cohort of pregnant women maintained on methadone. The incidence of NAS requiring pharmacotherapy did not differ significantly between women who decreased their dose of methadone (40\%) and those women who increased their dose of methadone (35\%) during pregnancy in this cohort.

Tapering opioid agonist medication before week 12 of pregnancy may increase the chance of spontaneous abortion, and tapering the dose after week 32 may lead to premature labor and birth [13]. Moreover, early case reports on opioid dependency in pregnancy documented cases of stillbirth and perinatal deaths after medical withdrawal $[24,25]$.

However, the literature on methadone-assisted withdrawal during pregnancy is sparse and inconclusive. Published studies have mainly reported findings from relatively short in-patient periods of withdrawal/tapering for heroin-dependent pregnant women $[11,12,14,26]$. Gradual tapers over a longer period of time for pregnant women stabilized on methadone or buprenorphine is the preferred method described in the United States and Norwegian treatment guidelines [8,27], if a woman chose to taper during pregnancy [28].

Research in Norway provides a unique opportunity to examine tapering from opioid agonist medication because many pregnant women in OMT have attempted tapering. Moreover, there is little use of illegal and legal drugs in this population that might confound the interpretation of findings related to tapering [29]. To our knowledge, this study will be the first to focus on tapering the methadone or buprenorphine dose for a group of pregnant women.

The overall aim of the study was to describe the tapering of opioid agonist medication in a cohort of pregnant women in Norway and the relationship between tapering and neonatal birth parameters and NAS. The specific study questions were:

(1) To what extent did the women taper their dose of methadone or buprenorphine during pregnancy?

(2) What were the characteristics of the women who tapered their OMT-medication dose compared to those women who did not?

(3) What were the birth and NAS parameters for the neonates of women, who tapered their dose of opioid agonist medication versus those women who did not taper their dose of methadone or buprenorphine during pregnancy?

\section{Materials and Methods}

In this study, tapering is used as the common term for all reductions in the OMT-medication dose during pregnancy for the women in our study. We do not have information about the OMTmedication dose-tapering schedule for each individual woman. In the standardized questionnaire, however, the Norwegian term for tapering was used (table 1).

The study included a national cohort of women in Norway maintained on either methadone or buprenorphine who gave birth from 1996 to 2009 and their neonates.

Throughout the course of the study, the national Norwegian OMT program had strict inclusion criteria and a high level of control, including regular urine screening for illicit/licit substance use [29]. Inclusion criteria for receiving OMT were minimum 25 years of age, five or more years of opioid dependency and prior attempts at abstinence-oriented treatment. Buprenorphine was introduced in Norwegian OMT programs in 2000 and has been the first line drug since 2005. Methadone and buprenorphine have been prescribed using the same national criteria for the treatment of opioid dependence, and are delivered by the same set of health professionals.

Patients received coordinated care by individualized multidisciplinary teams, including pregnancy follow-up, psychosocial care, continuous OMT and other specialized care needed for their substance use disorders. The lowest efficient dose of the OMT-medication was recommended throughout pregnancy with split dosing and/or increase in dose toward the end of pregnancy, if necessary [30].

\section{Participants}

Participants were recruited through the regional centers for OMT and through OMT service users' organizations. Based on data from the Norwegian Medical Birth Registry and the Norwegian 
Table 1. The questions about tapering of the methadone or buprenorphine medication dose for the pregnant women in opioid maintenance treatment (OMT)

1 What was the dose of methadone/buprenorphine when you realized that you were pregnant?

2 Did you attempt to taper the dose of OMT-medication during pregnancy? (no/yes)

3 In which pregnancy week was the tapering started?

4 What was the lowest dose of your OMT-medication during pregnancy?

5 In which pregnancy week did you stop the tapering?

6 What was the dose of methadone/buprenorphine at delivery?

The information concerning changes of the OMT-medication dose was also confirmed by health professionals.

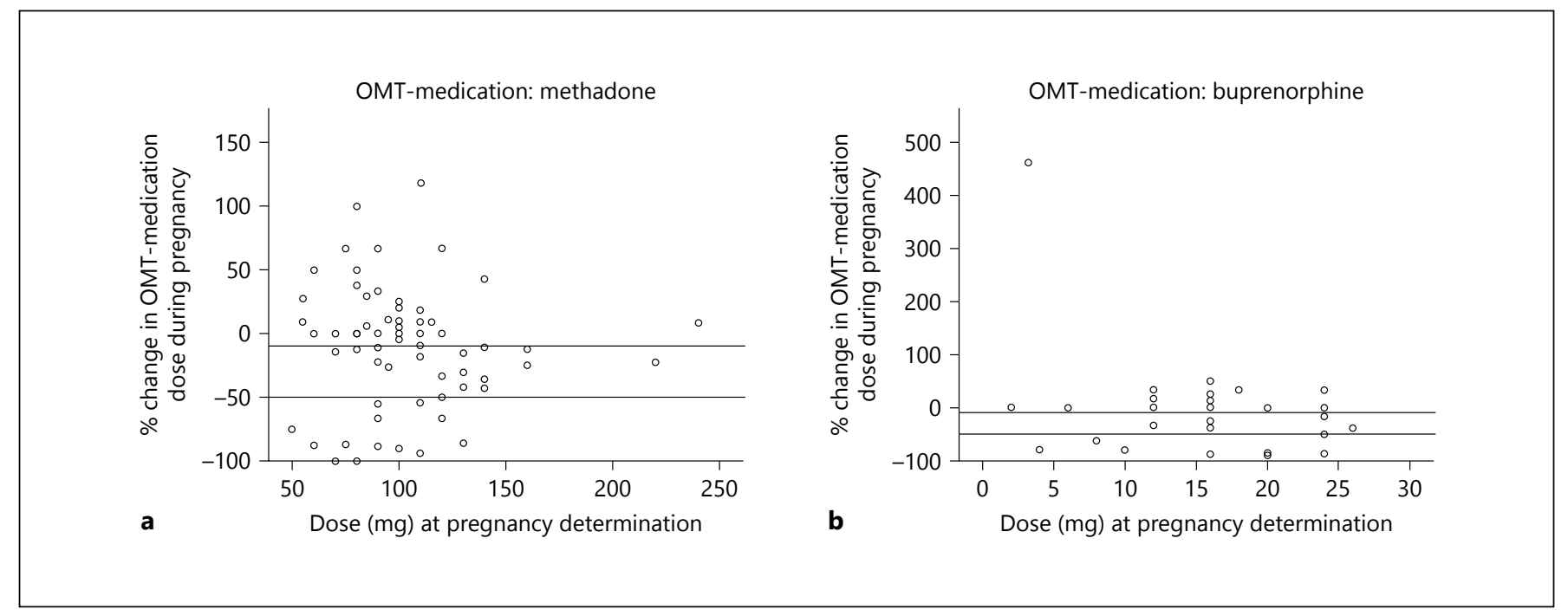

Fig. 1. The figures show the relationship between the OMT-medication dosages at the determination of pregnancy and the percentage change in OMT-medication dose from the determination of pregnancy until delivery. a Methadone. b Buprenorphine. The

Centre for Addiction Research, approximately 215 women in OMT had their first child between 1996 and 2009. We managed to recruit a total of 139 women who gave birth to 161 children in our study [29].

Only one child per participant was included in our analyses, to avoid dependency in the data by inclusion of siblings. Furthermore, we included only those women with at least two documented opioid medication dose levels in pregnancy. Sixteen women had fewer dose levels and were excluded. Thus, the final sample included a total of 123 women and their newborns: $80(65 \%)$ women in methadone maintenance treatment (MMT) and $43(35 \%)$ in buprenorphine maintenance treatment (BMT) in pregnancy. These women constituted $57 \%$ of the total population of pregnant women in OMT during the study period. However, we reached $75 \%$ of the target population, but for reasons mentioned above, we only included 123 women/neonates in this study.

Among women in our cohort who had more than one pregnancy, we chose their first pregnancy, while they were in OMT. vertical lines are drawn to show the cut-off for the different tapering groups: Group 1: below $-50 \%$. Group 2: between -50 and $-10 \%$. Group 3: above $-10 \%$.

Data were collected during three different time periods [29]. The first cohort was a retrospective study which took place from 1996 to $2003(n=35)$. The second cohort was a prospective study from January 2005 to February $2007(n=33)$ [31]. The third cohort was a retrospective study, including the years 2004 and from February 2007 to March 2009 ( $n=55)$.

Figure $1 \mathrm{a}$ and $\mathrm{b}$ show the relationship between the OMT-medication dose at determination of pregnancy and the percentage change in the OMT-medication dose from the determination of pregnancy until delivery, for all the women using methadone and buprenorphine, respectively. The women in the three cohorts were divided into three groups, irrespective of their cohort membership, depending on the degree of tapering from the determination of pregnancy until delivery: Group 1 tapered their OMT-medication dose more than 50\%, Group 2 tapered their OMT-medication dose between 11 and $50 \%$ and Group 3 had unchanged dose $( \pm 10 \%)$ or increased their OMT-medication dose during pregnancy (table 2). We divided the tapering group into two since it was the effect of tapering that we wanted to study specifically. 
Table 2. Comparing the opioid maintenance treatment (OMT)-medication dose when pregnancy was determined to the medication dose at delivery, both for the women who initiated tapering $(\mathrm{n}=75)$ and for the women who did not taper $(\mathrm{n}=48)$. The tapering/not tapering is defined as the difference in dose of OMT-medication at determination of pregnancy compared to the dose at delivery. Women using either methadone or buprenorphine during pregnancy in Norway $(1996-2009)(\mathrm{n}=123)$

\begin{tabular}{lccc}
\hline & Methadone, $\mathrm{n}(\%)$ & Buprenorphine, $\mathrm{n}(\%)$ & All, $\mathrm{n}(\%)$ \\
\hline Tried to taper $(\mathrm{n}=75)$ & & & Group \\
$\quad$ Off OMT-medication at delivery & $2(3)$ & 0 & $2(2)$ \\
$\quad$ Tapered $>50 \%$ & $12(15)$ & $7(16)$ & $19(15)$ \\
$\quad$ Tapered $11-50 \%$ & $18(23)$ & $12(28)$ & $30(24)$ \\
$\quad$ Unchanged dose $\pm 10 \%$ & $9(11)$ & $2(5)$ & $11(9)$ \\
$\quad$ Increased $>10 \%$ & $10(13)$ & $3(7)$ & $13(11)$ \\
Did not try to taper $(\mathrm{n}=48)$ & $18(23)$ & $13(30)$ & Group 1 \\
$\quad$ Unchanged dose $\pm 10 \%$ & $11(14)$ & $6(14)$ & $31(25)$ \\
$\quad$ Increased $>10 \%$ & $80(100)$ & $43(100)$ & $17(14)$ \\
\hline Total numbers & & Group 3 3 \\
\hline
\end{tabular}

Only one child of each woman in OMT during the period 1996-2009 was included. The first pregnancy was chosen when >1 delivery/woman.

Variables and Procedures

A standardized questionnaire was developed, based on the variables used in the international literature on methadone-exposed pregnancies [32]. The questionnaire explored demographic characteristics of women in OMT and their opioid agonist treatment, including the study questions shown in table 1 . The birth parameters, the neonatal outcomes and NAS scoring and treatment were also obtained by the questionnaire. Licit and illicit exposures to all medications, nicotine, alcohol and illicit substances during the current pregnancy were reported. Self-reports of licit and illicit substances were utilized because our earlier study showed that self-reporting documented some more substance use than the urine testing did [29].

In the first cohort, health care professionals filled in the questionnaire and thus ensured the quality of the data. The second cohort participated in a prospective study and data were collected in personal interviews in the last trimester and by telephone interviews three months after birth. Participants in the third cohort were interviewed on telephone after their child was born (median of 332 days), as part of a retrospective study. In the second and third cohorts, medical information, including the dose levels of opioid agonist medication and results of urine screening were confirmed by records from health professionals for $83 \%$ of the women. Similarly, hospital records concerning delivery, neonatal outcome, and NAS were collected for $93 \%$ of the participants in the second and third cohort. The collection of medical records from health professionals and hospitals secured the quality of the data for the second and third cohorts.

\section{Ethics}

The study was approved by the Regional Committee for Medical and Health Care Research Ethics (REC-number: S-07238b) and the Norwegian Data Inspectorate. The questionnaires from the first cohort were sent anonymously by the health professionals to the center for OMT in Oslo. In the two other cohorts, all the women gave written informed consent to take part in the study.

\section{Statistical Analysis Strategy}

Continuous variables were compared using independentsamples t-tests. Discrete variables were compared using $\chi^{2}$ tests. A significance level of $5 \%$ was chosen for all tests of significance. First, we conducted 'omnibus tests' that included all three groups of tapering/not tapering: one way ANOVA tests or $\chi^{2}$ tests, for continuous or discrete variables, respectively. Bivariate comparisons were conducted only if the 'omnibus tests' were significant. Data analyses were carried out using SPSS 22 for Windows.

\section{Results}

\section{Extent of Tapering}

Two women (2\%), both on methadone, but none on buprenorphine, managed to completely taper their OMTmedication during pregnancy (Group 1) (table 2). Nineteen women (15\%) tapered their opioid agonist medication more than $50 \%$ by the time of delivery compared to their dose at determination of pregnancy (Group 1). Thirty women (24\%) tapered their OMT-medication dose between 11 and 50\% (Group 2). Forty-two women (34\%) had unchanged dose until delivery, defined as $\pm 10 \%$ of the dose used at determination of pregnancy, while 30 women $(24 \%)$ increased their dose more than $10 \%$ during pregnancy (Group 3). There were no significant differences between women maintained on methadone compared to women maintained on buprenorphine with respect to the degree of tapering of their opioid agonist medication. 
Table 3. The opioid maintenance treatment (OMT)-medication dose levels at different stages of pregnancy for women in Norway $1996-$ 2009. A comparison between women who tapered their OMT-medication dose from determination of pregnancy until delivery and those who had stable or increased OMT-medication dose during pregnancy $(n=123)$

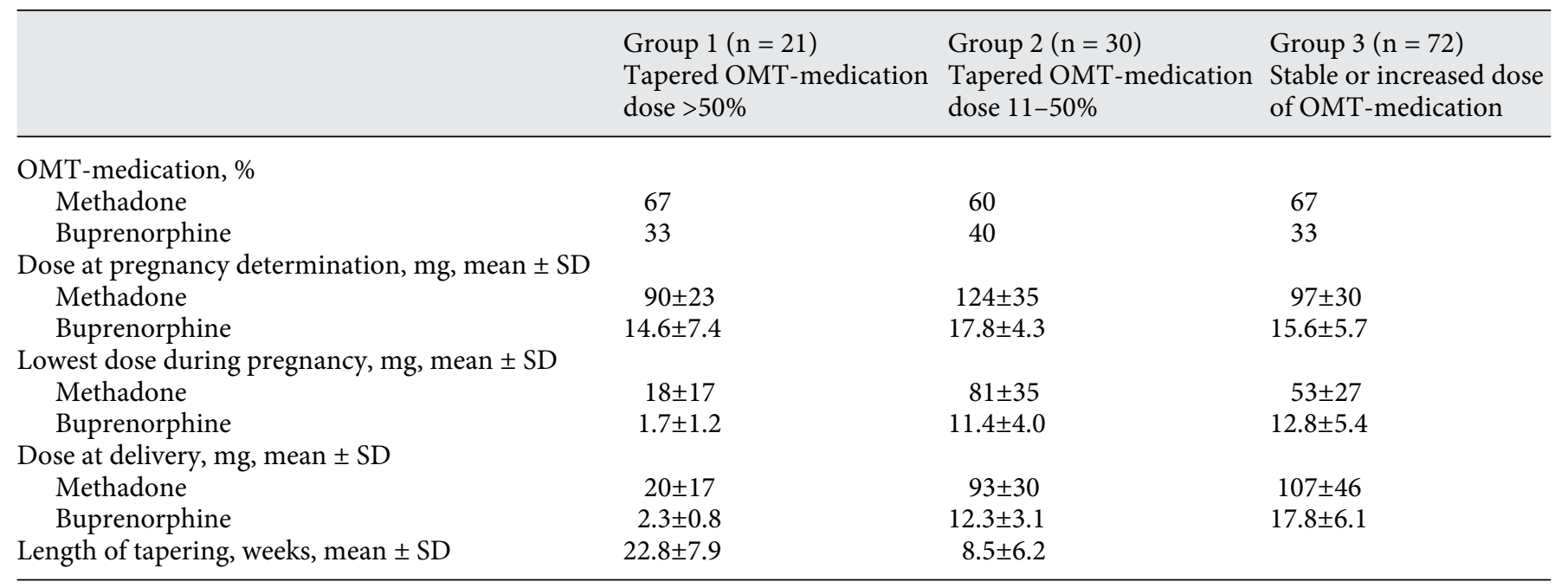

Table 3 shows the OMT-medication dose levels for the three groups at different stages during pregnancy. Group 1 spent $22.8 \pm 7.9$ weeks on tapering, while Group 2 spent $8.5 \pm 6.2$ weeks on tapering $(\mathrm{p}<0.001)$.

\section{Maternal Characteristics}

We compared the characteristics of all the three groups of tapering/not tapering women to each other (table 4). The women in Group 2 had significantly longer education compared with women in Group 3. No other significant differences were found in background characteristics between the groups.

The women in Group 1 were significantly more seldom smokers the last month before delivery, compared with women in Group 3. Concerning the use of drugs, the women in Group 1 did not use any opioids other than their OMT-medication or any benzodiazepines the last month before delivery.

\section{Neonatal Outcomes}

Bivariate analyses showed significant differences in birth weights of the neonates of women maintained on methadone in Group 1 compared to Group 2 (table 5). No other significant differences were found concerning neonatal growth parameters or incidence or length of pharmacological treatment of NAS between the different groups of women in the cohort. No unfavorable pregnancy outcomes, like preterm birth or reduced growth parameters, were found for the neonates of the tapering women.

Methadone Buprenorphine Pregnancy

Tapering Norway

\section{Discussion}

The first finding in our study was that approximately one fifth of the women tapered their dose of methadone or buprenorphine by more than $50 \%$ during pregnancy. The second finding was that the neonatal outcomes for the two tapering groups were, with one exception, not significantly different from the neonatal outcomes of the women who stayed on the same dose or increased their OMT-medication dose during pregnancy. The difference found was: increased birth weights of methadone-exposed neonates of the women who tapered more than $50 \%$ compared to the methadone-exposed neonates of women tapering $11-50 \%$. Notably, we did not find any unfavorable pregnancy outcomes for the neonates of the tapering mothers.

Only 2 of the women tapered their OMT-medication dose completely, while another $39 \%$ of the women reduced their dose by more than $10 \%$ from the time pregnancy was determined until delivery. This means that $41 \%$ of all the women tapered their dose by more than $10 \%$ during their pregnancy, a finding on level with the results in Cleary's study [23]. Most of the tapering in our cohort was done in mid-pregnancy, during a period of 8 to 23 weeks. The last half of the pregnancy is a period of rapid growth of the fetus with corresponding increase in the distribution volume of the OMT-medication. This means that women who stay on the same dose of medication will likely have a reduced blood plasma concentra- 
Table 4. The characteristics of the pregnant women, their opioid maintenance treatment (OMT), use of cigarettes and drugs during pregnancy in Norway 1996-2009. A comparison between women who tapered down their OMT-medication dose and those who had stable or increased medication dose during pregnancy $(n=123)$

\begin{tabular}{|c|c|c|c|}
\hline & $\begin{array}{l}\text { Group } 1(\mathrm{n}=21) \\
\text { Tapered OMT- } \\
\text { medication }>50 \%\end{array}$ & $\begin{array}{l}\text { Group } 2(\mathrm{n}=30) \\
\text { Tapered OMT- } \\
\text { medication } 11-50 \%\end{array}$ & $\begin{array}{l}\text { Group } 3(n=72) \\
\text { Stable or increased dose } \\
\text { of OMT-medication }\end{array}$ \\
\hline Age, years, mean \pm SD & $29.8 \pm 4.4$ & $31.8 \pm 4.4$ & $32.2 \pm 5.2$ \\
\hline Education, years, mean \pm SD & $10.9 \pm 1.9$ & $12.0 \pm 1.9^{*}$ & $10.7 \pm 1.8$ \\
\hline Opioid dependency prior to OMT, years, mean $\pm \mathrm{SD}^{\mathrm{a}}$ & $6.4 \pm 2.3$ & $7.8 \pm 2.9$ & $9.0 \pm 4.6$ \\
\hline Current pregnancy planned, $\%$ & 20 & 24 & 21 \\
\hline Current pregnancy confirmed in pregnancy week, mean \pm SD & $7.7 \pm 3.9$ & $8.3 \pm 4.8$ & $9.4 \pm 6.0$ \\
\hline \multicolumn{4}{|l|}{ OMT treatment } \\
\hline OMT started in current pregnancy, $\%$ & 5 & 0 & 10 \\
\hline In OMT prior to pregnancy, months, mean \pm SD & $30.4 \pm 18.3$ & $21.0 \pm 19.2$ & $24.7 \pm 23.8$ \\
\hline In-patient treatment $>20$ days during pregnancy, $\%$ & 52 & 37 & 35 \\
\hline Percentage smoking & 100 & 97 & 96 \\
\hline Numbers of cigarettes, mean \pm SD & $15.6 \pm 7.2$ & $14.7 \pm 5.1$ & $17.5 \pm 9.3$ \\
\hline \multicolumn{4}{|l|}{ Smoking 1 month prior to delivery } \\
\hline Percentage smoking & $67^{* *}$ & 83 & 92 \\
\hline Number of cigarettes, mean $\pm \mathrm{SD}$ & $7.0 \pm 9.3$ & $7.6 \pm 5.6$ & $9.0 \pm 6.1$ \\
\hline Use of other opiates, last month before delivery, \% & 0 & 0 & 9 \\
\hline Use of benzodiazepines last month before delivery, \% & 0 & 10 & 9 \\
\hline \multicolumn{4}{|l|}{$\begin{array}{l}\text { Use of other opiates, benzodiazepines, amphetamines } \\
\text { and/or cannabis (self-report and/or screening) }\end{array}$} \\
\hline Last month before pregnancy was confirmed, \% & 43 & 41 & 42 \\
\hline Last month before delivery, $\%$ & 10 & 17 & 15 \\
\hline
\end{tabular}

tion of their OMT-medication as the pregnancy develops, due to the increased distribution volume.

Studies of non-pregnant adults in OMT likewise find correspondingly low percentages for complete tapering [33-35]. However, pregnancy is probably a period where many women are highly motivated to taper their OMTmedication dose, especially if they think this option is best for their unborn babies. At the same time, tapering is probably more difficult in pregnancy, due to the increased fluid volume and other pregnancy changes in the body. We also know that there is a potential risk of increased mortality after the termination of OMT in adults [36-38].

Notably, the women who tapered the most (Group 1) were also the women who used least legal and illegal drugs the last month of pregnancy and also the women who smoked significantly more seldom than women who did not taper. There was no tendency for Group 1 to relapse to opioid use after the substantial taper they had accomplished.

Our results show that the women, who tapered their OMT-medication the most, more often stopped smoking than the women who did not taper. A decrease of 33\% in the smoking rate of Group 1 is substantial and may have impacted the neonatal outcome, even though the subsamples were too small to detect a significant effect.

Tapering the OMT-medication during pregnancy might lead to increased prenatal stress for the woman and the fetus [28]. Prenatal maternal stress has been shown to be associated not only with spontaneous abortion, preterm birth and growth-retardation for the fetus but also with long-term behavioral consequences, such as disorders in attention and learning difficulties in the offspring $[39,40]$. Effects of maternal exposure to social stress during pregnancy may lead to a variety of disadvantageous 
Table 5. Outcome for pregnancies and neonates of women in opioid maintenance treatment (OMT), who tapered down or stayed on the same dose/increased their OMT-medication dose during pregnancy $(\mathrm{n}=123)$

\begin{tabular}{|c|c|c|c|}
\hline & $\begin{array}{l}\text { Group } 1(\mathrm{n}=21) \\
\text { Tapered OMT- } \\
\text { medication }>50 \%\end{array}$ & $\begin{array}{l}\text { Group } 2(\mathrm{n}=30) \\
\text { Tapered OMT- } \\
\text { medication } 11-50 \%\end{array}$ & $\begin{array}{l}\text { Group } 3(n=72) \\
\text { Stable or increased dose } \\
\text { of OMT-medication }\end{array}$ \\
\hline \multicolumn{4}{|l|}{ Birth outcome } \\
\hline Caesarean section, $\%$ & 10 & 23 & 25 \\
\hline Gestational age at delivery, days, mean \pm SD & $277 \pm 12$ & $271 \pm 21$ & $271 \pm 19$ \\
\hline Methadone-exposed & $277 \pm 13$ & $265 \pm 23$ & $270 \pm 19$ \\
\hline Preterm birth <37 weeks, \% & 5 & 17 & 21 \\
\hline \multicolumn{4}{|l|}{ Neonatal growth } \\
\hline Birth weight, g, mean \pm SD & $3,245 \pm 514$ & $2,982 \pm 629$ & $3,037 \pm 673$ \\
\hline Methadone-exposed & $3,252 \pm 591^{*}$ & $2,667 \pm 604$ & $2,970 \pm 648$ \\
\hline Buprenorphine-exposed & $3,231 \pm 350$ & $3,454 \pm 272$ & $3,174 \pm 718$ \\
\hline Birth weight $<2,500 \mathrm{~g}, \%$ & 5 & 17 & 17 \\
\hline Methadone-exposed & $34.1 \pm 1.4$ & $32.8 \pm 2.9$ & $33.8 \pm 2.3$ \\
\hline Buprenorphine-exposed & $33.8 \pm 1.5$ & $34.7 \pm 1.2$ & $34.9 \pm 2.6$ \\
\hline Treated for NAS, \% & 38 & 63 & 62 \\
\hline Methadone-exposed & 36 & 61 & 62 \\
\hline Buprenorphine-exposed & 43 & 67 & 63 \\
\hline NAS, treatment duration, days, mean $\pm S D$ (no. of children) & $33.1 \pm 17.5(8)$ & $27.8 \pm 14.9(18)$ & $36.8 \pm 22.1(42)$ \\
\hline Methadone-exposed & $39.0 \pm 15.2(5)$ & $30.1 \pm 18.0(10)$ & $39.2 \pm 23.5(27)$ \\
\hline Buprenorphine-exposed & $23.3 \pm 19.7(3)$ & $24.9 \pm 10.3(8)$ & $32.4 \pm 19.2(15)$ \\
\hline
\end{tabular}

fetal and maternal outcomes [41]. These possible consequences of tapering the OMT-medication dose during pregnancy are seldom mentioned when discussing tapering in pregnancy.

Our results seem to support the main recommendation given by the World Health Organization and countries having evidence-based guidelines on opioid dependency in pregnancy: most pregnant women with opioid dependency should remain in opioid agonist pharmacotherapy with methadone or buprenorphine $[1,27]$.

It is important that addiction medicine experts are included in the comprehensive, multi-professional treatment approach of pregnant women in OMT. Every treatment decision should be based on a sound risk-benefit assessment; especially, every tapering decision should be discussed with and supervised by the treating physician.

The present study has a number of limitations. We might not have sufficient power to detect significant differences in our relatively small groups. On the other hand, we have the problem of multiple comparisons. The chance of finding spurious significant differences increases with the numbers of comparisons. Furthermore, because we only have the results for live births in our cohort, we do not know anything about early or late abortions or stillbirths for women commencing tapering.

We do not have measurements for maternal abstinence symptoms or well-being during tapering. Neither do we know why the women decided to taper their OMTmedication dose; if it was entirely their own decision or if the professionals performing their follow-up played any role. Nor do we have measurements of fetal well-being in the study. This means that we do not have an assessment of how the fetus is responding during tapering. The third cohort was interviewed retrospectively, 332 days after delivery. This might have led to some recall-bias. Our choice of using percentage change in OMT-medication dose during pregnancy as the measure for degree of tapering also has some limitations. Lastly, the way we have defined 
tapering in this study may differ from how the term tapering might be used in other settings.

The strengths of our study were several. To our knowledge, this was the first study of tapering of opioid agonist medication in pregnancy and the resulting neonatal outcomes for women on methadone or buprenorphine. Second, almost all the women in our study were stabilized on their OMT-medication from before the pregnancy started and were well controlled for legal and illegal drugs [29]. Third, the use of legal and illegal drugs is measured both by self-report and urine analyses. Finally, the study is a national cohort, with both methadone and buprenorphine treatment given in the same clinical settings and according to the same guidelines.

\section{Conclusions}

Some pregnant women maintained on methadone or buprenorphine are able to taper the dose of their medication dose substantially during pregnancy. Tapering more than $50 \%$ of the initial OMT-medication dose was associated with significantly higher birth-weights of methadone-exposed infants. However, other neonatal outcomes were not significantly different when the groups were compared. There was no apparent harm to mother or neonate linked to the tapering.

Pregnant women in OMT who taper their OMT-medication dose should be monitored closely during their tapering. We need studies that document the maternal well-being and the fetal safety of maternal tapering of the opioid agonist medication during pregnancy.

\section{Acknowledgments}

We would like to thank all the women who participated in our study and shared their experience.GKWS is grateful to the Norwegian Directorate of Health for giving her the opportunity to do research and her colleagues at the Norwegian Centre for Addiction Research for inspiring her through the course of the study. We would also like to thank Hendrée Jones from University of North Carolina at Chapel Hill for invaluable help with the language of the manuscript.

\section{References}

1 World Health Organization: Guidelines for the Psychosocially Assisted Pharmacological Treatment of Opioid Dependence. Geneva, WHO, 2009.

2 Jones HE, Martin PR, Heil SH, Kaltenbach K, Selby P, Coyle MG, Stine SM, O'Grady KE, Arria AM, Fischer G: Treatment of opioid-dependent pregnant women: clinical and research issues. J Subst Abuse Treat 2008;35:245-259.

-3 Jansson LM, Velez M, Harrow C: The opioidexposed newborn: assessment and pharmacologic management. J Opioid Manag 2009;5: $47-55$.

4 Finnegan LP, Connaughton JF Jr, Kron RE, Emich JP: Neonatal abstinence syndrome: assessment and management. Addict Dis 1975; 2:141-158.

5 McCarthy JJ: Intrauterine abstinence syndrome (IAS) during buprenorphine inductions and methadone tapers: can we assure the safety of the fetus? J Matern Fetal Neonatal Med 2012;25:109-112.

6 Jones HE, Kaltenbach K, Heil SH, Stine SM, Coyle MG, Arria AM, O'Grady KE, Selby P, Martin PR, Jansson L, Fischer G: Intrauterine abstinence syndrome (IAS) during buprenorphine inductions and methadone tapers: can we assure the safety of the fetus? J Matern Fetal Neonatal Med 2012;25:1197-1201.

7 World Health Organization: Guidelines for the Identification and Management of Substance Use and Substance Use Disorders in Pregnancy. Geneva, WHO, 2014.
8 Medication-Assisted Treatment for Opioid Addiction during Pregnancy. Rockville, Substance Abuse and Mental Health Services Administration, 2005.

9 National Clinical Guidelines for the Management of Drug Use during Pregnancy, Birth and the Early Development Years of the Newborn. New South Wales Government, Drug \& Alcohol Office, 2006.

10 Hepburn M: Drug use in pregnancy. Br J Hosp Med 1993;49:51-55.

-11 Dashe JS, Jackson GL, Olscher DA, Zane EH, Wendel GD Jr: Opioid detoxification in pregnancy. Obstet Gynecol 1998;92:854-858.

12 Stewart RD, Nelson DB, Adhikari EH, McIntire DD, Roberts SW, Dashe JS, Sheffield JS: The obstetrical and neonatal impact of maternal opioid detoxification in pregnancy. Am J Obstet Gynecol 2013;209:267.e1-e5.

13 Luty J, Nikolaou V, Bearn J: Is opiate detoxification unsafe in pregnancy? J Subst Abuse Treat 2003;24:363-367.

14 Jones HE, O'Grady KE, Malfi D, Tuten M: Methadone maintenance vs. methadone taper during pregnancy: maternal and neonatal outcomes. Am J Addict 2008;17:372-386.

15 McGlone L, Hamilton R, McCulloch DL, MacKinnon JR, Bradnam M, Mactier H: Visual outcome in infants born to drug-misusing mothers prescribed methadone in pregnancy. Br J Ophthalmol 2014;98:238-245.

16 Hamilton R, McGlone L, MacKinnon JR, Russell HC, Bradnam MS, Mactier H: Oph- thalmic, clinical and visual electrophysiological findings in children born to mothers prescribed substitute methadone in pregnancy. Br J Ophthalmol 2010;94:696-700.

17 Melinder A, Konijnenberg C, Sarfi M: Deviant smooth pursuit in preschool children exposed prenatally to methadone or buprenorphine and tobacco affects integrative visuomotor capabilities. Addiction 2013; 108: 2175-2182.

18 Jones HE, Jansson LM, O'Grady KE, Kaltenbach $\mathrm{K}$ : The relationship between maternal methadone dose at delivery and neonatal outcome: methodological and design considerations. Neurotoxicol Teratol 2013;39:110115 .

19 Jones HE, Dengler E, Garrison A, O'Grady $\mathrm{KE}$, Seashore C, Horton E, Andringa K, Jansson LM, Thorp J: Neonatal outcomes and their relationship to maternal buprenorphine dose during pregnancy. Drug Alcohol Depend 2014;134:414-417.

20 Dryden C, Young D, Hepburn M, Mactier H: Maternal methadone use in pregnancy: factors associated with the development of neonatal abstinence syndrome and implications for healthcare resources. BJOG 2009;116: 665-671.

21 Cleary BJ, Donnelly JM, Strawbridge JD, Gallagher PJ, Fahey T, White MJ, Murphy DJ: Methadone and perinatal outcomes: a retrospective cohort study. Am J Obstet Gynecol 2011;204:139.e1-e9. 
22 Cleary BJ, Donnelly J, Strawbridge J, Gallagher PJ, Fahey T, Clarke M, Murphy DJ: Methadone dose and neonatal abstinence syndrome-systematic review and meta-analysis. Addiction 2010;105:2071-2084.

23 Cleary BJ, Reynolds K, Eogan M, O'Connell MP, Fahey T, Gallagher PJ, Clarke T, White MJ, McDermott C, O'Sullivan A: Methadone dosing and prescribed medication use in a prospective cohort of opioid-dependent pregnant women. Addiction 2013;108:762-770.

-24 Blinick G, Wallach RC, Jerez E: Pregnancy in narcotics addicts treated by medical withdrawal. The methadone detoxification program. Am J Obstet Gynecol 1969;105:997-1003.

$\checkmark 25$ Rementeria JL, Nunag NN: Narcotic withdrawal in pregnancy: stillbirth incidence with a case report. Am J Obstet Gynecol 1973;116: $1152-1156$

26 Lund IO, Fitzsimons H, Tuten M, Chisolm MS, O'Grady KE, Jones HE: Comparing methadone and buprenorphine maintenance with methadone-assisted withdrawal for the treatment of opioid dependence during pregnancy: maternal and neonatal outcomes. Subst Abuse Rehabil 2012;3(suppl 1):17-25.

27 Welle-Strand GK, Bakstad B: National Clinical Guideline for Opioid Maintenance Treatment in Pregnancy and the Follow-Up of the Children and Families until School-Age. Oslo, Norwegian Directorate of Health, 2011.

28 Welle-Strand GK, Kvamme O, Andreassen A, Ravndal E: A woman's experience of tapering from buprenorphine during pregnancy. BMJ Case Rep 2014; DOI: $10.1136 /$ bcr-2014207207.
29 Welle-Strand GK, Skurtveit S, Jones HE, Waal H, Bakstad B, Bjarkø L, Ravndal E: Neonatal outcomes following in utero exposure to methadone or buprenorphine: a national cohort study of opioid-agonist treatment of pregnant women in Norway from 1996 to 2009. Drug Alcohol Depend 2013;127:200206.

30 Welle-Strand GK, Waal H: Guidance for Medication Assisted Rehabilitation in Pregnancy (Norwegian Only). Oslo, National Center for Opioid Maintenance Treatment, 2001.

31 Bakstad B, Sarfi M, Welle-Strand GK, Ravndal E: Opioid maintenance treatment during pregnancy: occurrence and severity of neonatal abstinence syndrome. A national prospective study. Eur Addict Res 2009;15:128-134.

32 Welle-Strand GK: Questionnaire for Pregnancy/Birth in Opioid Maintenance Treatment (OMT) (Norwegian Only). Oslo, National Center for Opioid Maintenance Treatment, 1999.

33 Weiss RD, Potter JS, Fiellin DA, Byrne M, Connery HS, Dickinson W, Gardin J, Griffin ML, Gourevitch MN, Haller DL, et al: Adjunctive counseling during brief and extended buprenorphine-naloxone treatment for prescription opioid dependence: a 2-phase randomized controlled trial. Arch Gen Psychiatry 2011;68:1238-1246.
34 Calsyn DA, Malcy JA, Saxon AJ: Slow tapering from methadone maintenance in a program encouraging indefinite maintenance. J Subst Abuse Treat 2006;30:159-163.

35 Kornør H, Waal H: From opioid maintenance to abstinence: a literature review. Drug Alcohol Rev 2005;24:267-274.

36 Kornør H, Waal H, Sandvik L: Time-limited buprenorphine replacement therapy for opioid dependence: 2-year follow-up outcomes in relation to programme completion and current agonist therapy status. Drug Alcohol Rev 2007;26:135-141.

37 Clausen T, Anchersen K, Waal H: Mortality prior to, during and after opioid maintenance treatment (OMT): a national prospective cross-registry study. Drug Alcohol Depend 2008;94:151-157.

38 Cousins G, Teljeur C, Motterlini N, McCowan C, Dimitrov BD, Fahey T: Risk of drugrelated mortality during periods of transition in methadone maintenance treatment: a cohort study. J Subst Abuse Treat 2011;41:252260.

39 Mulder EJ, Robles de Medina PG, Huizink AC, Van den Bergh BR, Buitelaar JK, Visser GH: Prenatal maternal stress: effects on pregnancy and the (unborn) child. Early Hum Dev 2002;70:3-14.

40 Weinstock M: The long-term behavioural consequences of prenatal stress. Neurosci Biobehav Rev 2008;32:1073-1086.

-41 Brunton PJ: Effects of maternal exposure to social stress during pregnancy: consequences for mother and offspring. Reproduction 2013; 146:R175-R189. 